\title{
Response to the health and nutrition needs of people affected by drought emergency in Southeast Ethiopia
}

\author{
Amare Deribew ${ }^{1}$, Fessehaye Alemseged ${ }^{1}$
}

\begin{abstract}
Background: Without well organized preparedness, early warning system and response, the consequence of drought would be catastrophic.

Objective: The objective of this study was to assess the preparedness and response of different sectors for health and nutrition needs of people affected by drought in Southeast Ethiopia.

Methods: This assessment was conducted from August 14 to September 7, 2006 in Borena, Afder and Liben zones in the Southeast Ethiopia. Interview with representatives of governmental and non-governmental organizations, record review, and focus group discussion with community leaders were done to assess the health and nutrition related responses of the different stakeholders.

Results: Disaster Preparedness and Prevention Commissions (DPPC) at district level did not have documented contingency planning, vulnerability assessment and risk mapping and zoning related to drought emergency. Most of the districts' health offices had no adequate human resources to respond to drought emergency. The surveillance system was not functional in all Districts. Eighty percent of the health institutions did not conduct nutritional survey or screening. None of the health facilities had temporary or therapeutic feeding centres. Most of the focus group discussants mentioned that the food and non-food aid was not timely and adequate.

Conclusions: Absence of infrastructure, lack of human resources, absence of functional surveillance system, and weakness of DPPC offices were the serious bottlenecks which affected the health and nutrition related response of the drought emergency. [Ethiop. J. Health Dev. 2009;23(2):169-171]
\end{abstract}

\section{Introduction}

About 10 percent of the Ethiopian population are lowlanders and majority of them are engaged in extensive livestock herding, which forms the backbone of their economy. In these areas drought occurs as a result of lack of rain over one or more rainfall seasons (1).

In 2006, the successive years of drought, failed seasons, livestock losses, elevated staple food prices, and asset depletion had placed about 11 million people in the need of humanitarian assistance and the resulting food insecurity had placed some 2.6 million people in need of emergency assistance and support in Ethiopia. Many of those in need were pastoralists or agro-pastoralists in Southern Somali Region and Borena Zone of Oromiya Region, where livelihoods depend on the fertility of the soil and the health of the livestock, both of which had been seriously compromised. Despite significant attention from the Ethiopian government and donors, food insecurity and malnutrition in affected areas remained critical at that time $(2,3)$.

Cognizant of the above facts, this assessment was carried out to examine preparedness and response of governmental and non-governmental organizations in addressing health and nutrition needs of the drought affected people in the Southeast Ethiopia. As a result, the study had forwarded viable recommendations that contribute for long-term alleviation of the problems related to frequent drought.

\section{Methods}

This cross sectional qualitative and quantitative survey was conducted from April 14, 2006 to September 7, 2006 in the drought affected districts in Southeast Ethiopia specifically in Borena zone of Oromiya Regional state and Afeder and Liben zones of Somali Regional state. In Borena zone, three districts namely Teltele, Arero and Moyale were selected randomly. In Afder Zone and Liben Zones of Somali regional state, two districts namely, Dolobay and Hudet were selected respectively. In the selected districts, interview with heads of the health centers, NGOs and Disaster Prevention and Preparedness Commissions (DPPC) were done using semi-structured questionnaire. The content of the questionnaire included: availability of contingency plans; presence of policies, guidelines and early warning system for drought; availability of human and material resource to manage drought emergency; functionality of the surveillance system; adequacy and timeliness of the food, health and non-food aids after the disaster and presence of developmental activities. Record reviews were also done in all district offices, health institutions, and NGOs. For Focus group discussions (FGDs), two kebeles (smaller administrative units), one from the highly drought affected kebeles and the other from the relatively less affected ones, were selected from each study District. Two FGDs were conducted in each of the

Department of Epidemiology and Biostatistics, Jimma University, P.O.BOX: 205, Jimma, Email:

amare.deribew@ju.edu.et /amare deribew@yahoo.com 
selected kebele. Each FGD consisted of 8-10 community leaders. The participants were selected by convenient sampling. Data were collected by trained health officers. The investigators strictly supervised the data collection process. To do descriptive statistics and calculate percentages, the quantitative data were entered into SPSS 12.0 statistical software. The qualitative information collected from field was transcribed by the data collectors immediately after the interview. After several readings, key categories \& themes were developed. Finally, the data were interpreted and presented using respondents' own words as illustration.

Permission letter from World Health Organization (WHO) country office was given to each administration offices, health services and other NGOs. Purpose of the assessment was explained to the participants of the study and verbal consent was obtained from the respondents before data collection.

\section{Results}

Almost all of the Woreda DPPC offices in both Oromiya and Somali regions had no documented contingency planning, vulnerability assessment and risk mapping and zoning related to drought emergency. From the five woredas, $4(80 \%)$ had early warning system using indicators such as amount and frequency of rainfall by seasonal forecast, level of stream and pond water, livestock conditions such as emaciation and availability of pasture. Regarding the response to drought emergency, none of the DPPC offices at district, Zonal and regional levels had any role to give food and non-food aids at the spot. Food aids came directly from the Federal DPPC Office by request or after assessment every 6 months.

The numbers of health professionals who were health assistants and or nurses in most of the districts were less than five. Similarly, most of the health centers $(80 \%)$ did not have adequate and trained human resources. World Health Organization (WHO) had deployed a total of 10 health workers in six health centers.

The surveillance system in the study area was very poor. Most of the core functions of surveillance system such as weekly and monthly reporting; analysis of data by time and place; availability of action threshold for epidemic prone diseases were not in place in many of the district health offices and health centers. Regarding nutrition related responses, none of the district health offices had temporary treatment shelters. From 5 District health offices, $2(40 \%)$ of them were involved in screening of malnutrition in collaboration with other NGOs. Eighty percent of health centers didn't conduct nutritional survey or screening. Regular growth monitoring was not done in all of the health facilities. None of the health facilities had temporary feeding centres and all of them didn't open therapeutic feeding centres nor gave supplementary feeding.
Only few NGOs like Care-Ethiopia and International Medical Corps (IMC) had community based therapeutic centers and supplementary feeding programs. CareEthiopia had also done other activities such as water rationing, emergency livestock feeding, emergency destocking and processing of dry meat and capacity strengthening through training. UNICEF-Ethiopia in collaboration with the Borena Zonal health office had set up seven emergency health and nutrition mobile team in the drought affected woredas of Borena zone to respond to the health needs of the pastoral community affected by the drought. The mobile team had been providing curative and immunization services. From nine NGOs, five $(55.5 \%)$ of them were engaged in some developmental activities including water projects, distribution of seeds and tools for farmers and asset diversification in some accessible woredas of Borena zone. Almost all NGOs were engaged in water development projects like boreholes drilling, rehabilitation of traditional wells and construction of new wells.

For the qualitative study, a total of 87 FGD participants were included. First the perception of the community about disaster in general and drought in particular were assessed. Many of the participants at Borena Zone said that drought, malaria epidemic and disease of livestock particularly Gendi (trypanosomiasis) were the major disasters in the community. Participants at Afder and Liben Zones on the other hand said that drought and conflict were the major disaster that threatened the community by causing many death and migration of people. Almost all FGD participants stated God's/Allah's anger as the cause of the drought. A 50 years old community leader at Dolobay Woreda said 'Drought is the result of our sins ordered by Allah since we are committing serious mistakes by killing each other.' Participants in some woredas mentioned that there are some stars in the sky that indicate the occurrence of drought ahead of time. The community complained about the untimely food and non-food aid by the other sectors. It was explained that food and non-food aid reached the affected people after 3-4 months of the occurrence of drought. A 60 years old man explained the untimely food aid by saying "little amount of food aid comes after many people were dead and buried. It seemed that the food aid came for funeral purposes." Regarding the quantity of food aid, it was said that $15 \mathrm{~kg} /$ person $/$ month cereals were given for selected individuals who had lost all assets (livestock). To express the small quantity of food aid, a 60 years old man bitterly said "how could $15 \mathrm{~kg}$ cereals be adequate in a household with 10 people. This amount of food couldn't be enough even for chickens." 'The type of food aid given was mainly cereals. Similarly, a 45 years old woman at Liben Zone said " they gave us only wheat. We don't have any mills to grind it. Giving this unprocessed wheat to children and lactating mothers causes diarrhoeal diseases. 
Children and mothers are accustomed to camels' milk. Now we don't have it since our camels are dead."

\section{Discussion}

The DPPC offices at District level had no adequate human resources and were very weak to do risk mapping and zoning as well as vulnerability assessment. Such centralized structure of DPPC office might be one of the reasons for the delay of humanitarian assistant during drought emergency. The early warning systems such as livestock conditions, migration and malnutrition are the late manifestation of drought emergency. Using such early warning system could also contribute to the delay of food and non-food aids.

The absence of functional surveillance system such as case detection, data analysis, reporting, feedback and supervision would delay the undertaking of prompt prevention and control activities. The role of the government health sectors in responds to nutritional needs of the drought affected people was also very minimal. This may be due to inadequate financial and trained human resource and weak logistic readiness. There might also be high expectation by government from NGOs to address the need, creating a dependency syndrome leading to weak participation of the community with negative impact in alleviating nutritional problems of the affected population.

The FGD participants stated that $15 \mathrm{~kg}$ of cereals (wheat) were given for a household per month which might consist of 10 family members. Such amount of cereals gives $168 \mathrm{Kcal} /$ day, which is much below the sphere standard, $2100 \mathrm{Kcal} /$ day (4-5) of person's need.
In conclusions, absence of infrastructure, lack of human resources, almost non-existent viable surveillance system, weakness of DPPC offices and health institutions at district level to do risk mapping and vulnerability assessment and untimely response were the serious bottlenecks which affected the health and nutrition related response of the drought emergency. The study community had low awareness of the causes and preventive methods of drought. DPPC at District level should be empowered to detect and manage drought emergency at its early stage. The early warning system of drought should not be dependent on late manifestation of drought. A combination of metrological, hydrological and agricultural indicators of early warning system should be used. The community should be educated about drought and its preventive strategies.

\section{Acknowledgments}

We would like to thank WHO-country representative office for funding the study. We thank the study community and the different organizations for their support in providing us the necessary information.

\section{References}

1. UNDP. Emergencies Unit for Ethiopia. Drought Contingency Planning to Support Pastoralist Livelihoods in Ethiopia. Addis Ababa Ethiopia, 1997

2. WWW.Reliefweb.com. ETHIOPIA Food Security Update April 2006, accessed on December, 2006.

3. International Federation of Red Cross and Red Crescent Societies. Drought in Ethiopia. April 2006.

4. WHO. The Sphere Project: Humanitarian Charter and Minimum Standards in Disaster Response. WHO, Geneva, 2004.

5. WHO. The Sphere Project: Minimum standards in water and sanitation. WHO, Geneva, 2004. 